MLM-2391

\title{
MLM-2391
}

\section{A Survey of Large-Scale Isotope \\ Applications: Nuclear Technology Field}

\author{
Robert De Witt
}

January 21, 1977

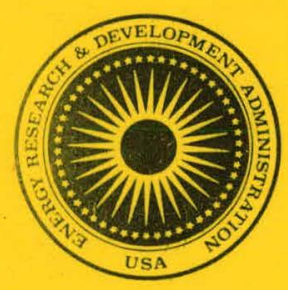

Monsanto

\section{MOUND LABORATORY}

Miamisburg, Ohio

operated by

\section{MONSANTO RESEARCH CORPORATION}

a subsidiary of Monsanto Company

for the

UNITED STATES ENERGY RESEARCH AND DEVELOPMENT ADMINISTRATION

U.S. Government Contract No. EY-76-C-04-0053 


\section{DISCLAIMER}

This report was prepared as an account of work sponsored by an agency of the United States Government. Neither the United States Government nor any agency Thereof, nor any of their employees, makes any warranty, express or implied, or assumes any legal liability or responsibility for the accuracy, completeness, or usefulness of any information, apparatus, product, or process disclosed, or represents that its use would not infringe privately owned rights. Reference herein to any specific commercial product, process, or service by trade name, trademark, manufacturer, or otherwise does not necessarily constitute or imply its endorsement, recommendation, or favoring by the United States Government or any agency thereof. The views and opinions of authors expressed herein do not necessarily state or reflect those of the United States Government or any agency thereof. 


\section{DISCLAIMER}

Portions of this document may be illegible in electronic image products. Images are produced from the best available original document. 
This report was prepared as an account of work sponsored by the United States Government. Neither the United States nor the United States Energy Research and Development Administration, nor any of their employees, nor any of their

implied, or assumes any legal liability or responsibility for the accuracy, com-

pleteness or usefulness of any information, apparatus, product or process disclosed

or represents that its use would not infringe privately owned rights. 


\title{
A Survey of Large-Scale Isotope Applications :
}

\author{
Nuclear Technology Field
}

Robert De Witt

Issued: January 21, 1977

PATENT HOLD

This report contains possibly patentable subject matter and is made availabte in confidence. for use onty in performance of work by or for the USERDA, its contents should not be publisfec further dis seminated, or ysed for other purposes until patent clearance has been accorded by the Assistant General Counsel-for Patents, USERDA, Headquarters.

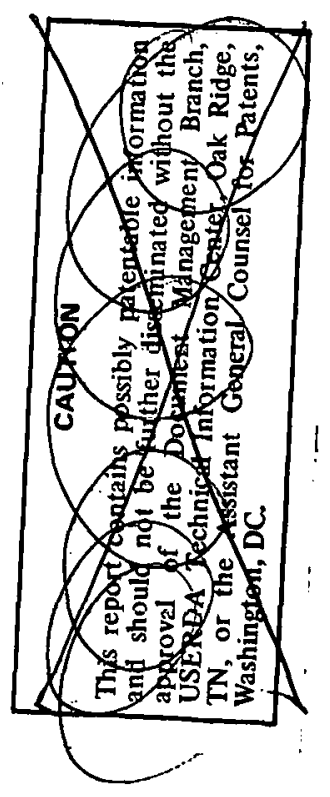

\section{MONSANTO RESEARCH CORPORATION}

A Subsidiary of Monsanto Company

\section{MOUND LABORATORY}

Miamisburg, Ohio

45342

operated for

\section{UNITED STATES ENERGY RESEARCH AND.DEVELOPMENT ADMINISTRATION}

This repost was prepared as an account of work sponsored by the United States Covernment. Neither the Uniled Stales nar the Unied Slates Energo their employes, ins subcontractors, ot their employees, makes any warrenty, express or implied, or assumes any legal liability or responsibility for the accuracy, completeness or ueffulness of ally information, appanatils, prontuct or process disclosed, or represents that its use wutho mo

\section{U. S. Government Contract No. EY-76-C-04-0053}




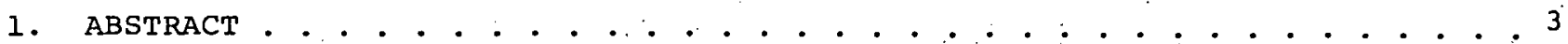

2. INTRODUCTION. : . . . . . . . . . . . . . . . . . . . . . . . . 3

3. SUMMARY . . . . . . . . . . . . . . . . . . . . . . . . . . . . 3

4. POTENTIAL ISOTOPE APPLICATIONS ON A GRAM SCALE ... . . . . . . . . . . . . . 4

5. AVAILABILITY OF ISSOTOPES FOR GRAM-SCALE APPLICATIONS . . . . . . . . . . 4

6. POTENTIAL ISOTOPE APPLICATIONS ON A TONNAGE SCALE . ... . . . . . . . . . 5

7. "EPIT" MATERIAL APPLICATIONS IN THE NUCLEAR FIELD . . . . . . . . . . . . . 5

7.1. Thermal Reactors . . . . . . . . . . . . . . . . . . . 6

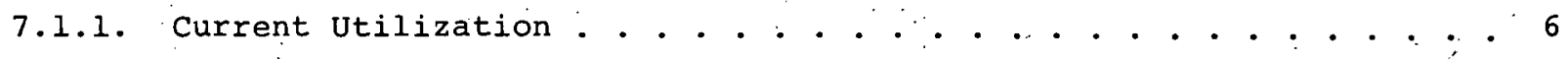

7:1.2. Future Trends : . . . . . . . . . . . . . . . . . . . . . . . 7

7.2. Breeder Reactor Systems . . . . . . . . . . . . . . . . . . . . . 8

7.3. Potential "EPIT" Materials in CTR Systems . . . . . . . . . . . . . . 9

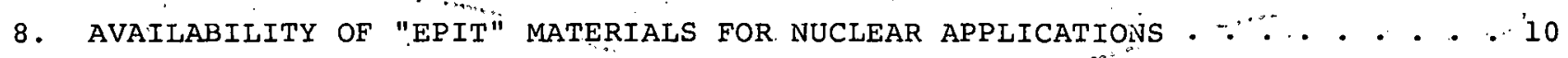

9. "EPIT" MATERIALS FROM NUCLEAR, WÁSTES FOR BENEFICIÁL USES • • • • • • • • • 14

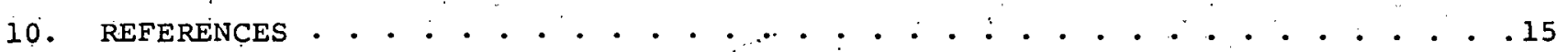




\section{ABSTRACT}

A preliminary literature survey of potential large-scale isotope applications was made according to topical fields; i.e., nuclear, biological, medical, environmental, agricultural, geological; and industrial. Other than the possible expansion of established large-scale. isotope apdications such as uranium, boron, lithium, and hydrogen, no new immediate isotope usage appears to be developing. Over the long term a change in emphasis for isotope applications was identified which appears to be more responsive to societal concerns for health, the environment, and the conservation of materials and energy. For gram-scale applications, a variety of isotopes may be required for use as nonradioactive "activable" tracers. A more detailed survey of the nuclear field identified a potential. need for large amounts (tons) of special isotopic materials for advanced reactor components and structures. As this need for special materials and the development of efficient separation methods progresses, the utilization of isotopes from nuclear wastes for beneficial uses should also progress.

\section{INTRODUCTION}

This report presents the results of a survey. to identify large-scale usage trends in isotope applications. The information is needed to establish a priority for the development of the chemical and isotope separation methods that are required to provide the large quantities (tons) of isotopes for which no adequate, large-scale, production processes exist. A preliminary literature survey was conducted according to topical fields of applications; i.e., nuclear, biological and medical, agricultural, environmental, geological, and industrial. For near-term applications, this survey showed that other than the possible expansion of those already well-established isotope applications, i.e., uranium, lithium, boron, etc., no new isotope applications appear to be developing. However, over the long term there appears to be a trend towards a change in the emphasis fur isutope applications. In the past, isotope usage emphasis has bcen in the area of nuclear fuels for power production, while future applications appear to be more responsive to the societal concerns for the environment and the conservation of materials and energy.

Tlis trend is copecially noticeable in the nuclear field which historically has utilized large amounts of high-purity. isotopes and shows promise of still greater isotope utilization. For this reason, the survey was narrowed specifically to this field, and a concentrated effort to identify future isotope application in the nuclear field was initiated. The literature; visits to ERDA, university, and private industrial laboratories; attendance at professional conferences; and professional consultations were used in this part of the survey effort.

The result of the prelininary literature survey is summarized, followed by a brief discussion of the potential gram-scale isotope application which appears to be developing. The remainder of the report deals with a detailed discussion of the potential isotope applications in the nuclear field.

\section{SUMMARY}

Trends in potential isotope applications identified in the preliminary literature survey can be divided into two scales: 1) gram-quantity applications and 2) tonnage-quantity applications. Gram- 
quantity usage is characteristic of all fields of applications except the nuclear field, whereas tonnage quantity usage is at present characteristic of the nuclear field only. These trends are summarized below.

i. The largest variety of isotope applications occurs in nonnuclear fields, especially in the biological and medical field. However, most applications appear to require at most only gram amounts.

ii. The greatest potential for largescale (tonnage) usage exists in the nuclear field (fuel cycle, shielding, moderators, materials for reactor construction, gas tagging fuel elements, and beneficial use of isotopes from nuclear wastes).

iii. A concerted effort is under way in all fields to either substitute or complement radioactive isotopes with stable isotopes in light of societal concerns and improved, moresensitive analytical techniques for detection of stable isotopes.

Two major obstacles to large-scale usage of chemically pure isotopes are the lack of physical property data for performance evaluations and the availability and estimated costs for large quantities of these materials. However, significant progress is being made to overcome these obstacles.

\section{POTENTIAL ISOTOPE APPLICATIONS ON A GRAM SCALE}

Except in the nuclear field, a potential for gram or greater amounts of a variety of isotopes is developing for use as nonradioactive activable tracers. This trend is especially strong in medical diagnostics and criminalistics. Although it is not expected that these applications will ever require tonnage amounts, it does appear that certain uses could grow to employ amounts substantially greater than can be reasonably and economically supplied by the Calutrons.

Activable tracers are reported to play an important role in: 1) criminalistics, 1 2) process flow rate studies, ${ }^{2}$ ground water characterization, air and water pollution studies, ${ }^{3}{ }^{4}$ and medical diagnostics (human body function studies) $.5,6,7,6$

In general, natural abundance material is used for tracer applications; however the use of enriched isotopes for many applications would improve the sensitivity of the analysis. In criminalistics, high purity europium oxide (\$500/1b) has been proposed to tag gun powder. Isotopes that have been considered as activable tracers in water treatment system studies $^{2}, 4$ are scandium-45, chromium-50, manganese-55, cobalt-59, bromine-81, molybdenum-98, indium-115, cerium-140, cerium-142, and tantalum-181. For field studies $^{3}$ of the dietary habits of desert rodents the isotopes dysprosium-165, indium-115, iodine-128, bromine-80, and chlorine -38 have been used. Activable tracers which have been found useful in medical studies ${ }^{5,6}$ are chromium-50, chromium-51, iron-58, selenium-75, selenium-74, and potassium-40. Double activable tracer labeling, for example chromium-50 and iron-58, has been found especially useful in investigation of iron metabolism in pregnant patients.

\section{AVAILABILITY OF ISOTOPES FOR GRAM- SCALE APPLICATIONS}

The future growth in isotope applications on a gram-scale level at the present time appears to be limited more by the lack of a general understanding of the benefits obtainable by their use rather than by the availability or cost of the applications of the isotopes. This is especially true of the application of the "activable tracers." However, as the knowledge of these applications becomes widespread, the future applications could expand so that their usage could be possibly hampered by isotope scarcity and expense. With the new developments in laser isotope separations, ${ }^{9}$ recent advances in chemical exchange isotope separations methods, 10 and the new techniques for isotope separations that are being devised, it appears that isotope availability will not present any long-term problems. Based on present known separation methods, 1 many of the 1800 known nuclides can be made available in gram quantities at reasonable costs. 
For example, both sulfur 12,13 and chlorine ${ }^{2}$ are presently available from Mound Laboratory in gram amounts for less than a few hundred dollars per gram. Isotope price reductions are limited in most cases by the scale of production, which is determined by the market demand, than by the state of the technology. For example, the capability for producing large amounts of nitrogen-15 at costs less than one dollar per gram has existed for some time. Deuterium in the form of heavy water also has been available in large quantities at very reasonable prices.

\section{POTENTIAL ISOTOPE APPLICATTONS ON A TONNAGE, SCALE}

The present energy crisis has dramatically accelerated the development of advanced nuclear energy systems. Rapidly growing requircments for resources (energy, material, and financial) usualiy follow the development of any major energy system. It is generally accepted $14,15,16$ that these new developments be accomplished with optimum use of resources and minimum impact on the environment. The major isotope resource problem in nuclear eneryy systems was tonnage amounts of nuclear fuel. Availability, nuclear composition, elemental purity, and generated nuclear wastes are of major concern. But since future energy systems are to be based on unlimited, relatively pollution-free fuel resources; a new priority is evolving concerning special construction materials.

Many of the special materials that are needed ${ }^{17}$ in tonnage amounts in the construction of the proposed nuclear energy systems are either very scarce and expensive or very difficult and costly to fabricate. It is, therefore, necessary to consider their conservation and optimal use. In some cases, it may be necessary to collect and atore ecarce materials for future use. In other cases, material recycle may be the answer. Examples of materials which should be conserved are lithium and helium. The future projected requirements for lithium and helium in proposed breeder and controlled thermonuclear reactors (CTR), if adopted, could, be quite large. Lithium, which $i s$ of limited availability, ${ }^{19}$ could become scarce by fused salt battery consumption. Helium scarcity and expense 20 can result from atmospheric venting with the burning of natural gas.

In other cases, entirely new considerations have to be introduced to optimize the use of scarce and expensive materials. Conservation and optimized uses for scarce construction materials in the breeder reactor and the CTR can be accomplished through a consideration of neutron interactions with various constituent isotopes. These considerations will require the manufacture and characterization of materials having lower element impurity and unnatural isotope abundance. Such materials can be referred to as elementally pure-isotopically tailored ("EPIT") materials.' Thè proper use of such materials could result in an optimized nuclear energy system which would be longer lasting, more reliable, more economical, and less polluting than one using ordinary materials of construction. Such favorable results could more than pay for the cost of special preparation.

\section{7. "EPIT" MATERIAL APPLICATIONS IN THE NUCLEAR FIELD}

The application of any material, regardiess of its use, is determined by its availability, physical and chemical properties, material performance, and allowable cost. In addition, of late, the energy content and the impact of its use on the environment play an important role in determining public acceptance of a material. These same factors will effect the adoption of any new "EPIT" materials in the nuclear field. In past "EPIT" materials applications, elemental purity was established as an. important material property not only from economical; but also from environmental considerations. This has been especially true in the selection of nuclear fuel, moderator, and shielding materials.

The nuclides of uranium, thorium, plutonium, hydrogen, boron, lithium, cadmium, and gallium are well known. For the most part, the "EPIT" concept has been implemented in the fabrication of these materials. However, little has been done with the use of the "EPIT" materials concept to optimize the fuel cladding and 
reactor structural materials such as iron, nickel, chromium, titanium, and zirconium. It is in these areas that the "EPIT" concept can allow the necessary options for conservation and optimization of material use, especially in nuclear energy systems.

Prerequisite to the ultimate goal of an unlimited, pollution-free, economical, reliable nuclear energy system, are solutions to the material problems resulting from the interaction(s) of radiation with structural containment materials. These problems, if allowed to go unresolved, could have an economic impact 21,22 which is measured in the bilitions of dollars per year. This cost penalty can be minimized by the effective utilization of the "EPIT" materials concept. Some examples of the potential "EPIT" material application and their beneficial characteristic(s) are identified in a qualitative manner, below.

Before serious considerations of the "EPIT" materials application can be entertained, quantitative evaluations will have to be made. For these evaluations, data concerning material needs, performance, and allowable costs will have to be generated. Unfortunately, the necessary data do not exist at the present time for most future "EPIT" material evaluations. Our objective here is to identify some nuclear reactor structural materials for which elemental purification and/or isotopic tailoring could provide material properties which have the potential to make substantial improvements in reactor designs. Where sufficient data exist, semiquantitative evaluations of such uses are made.

The properties of materials most sensitive for use in the nuclear energy field are the fission cross sections, neutron absorption cross sections, and activation and transmutation products that are the products of the interaction of neutrons with reactor materials.

Reactor characteristics that are mostly affected by material properties are 1) neutron economy, 2) reactor operating efficiency (lifetime and reliability), and 3) environmental impact (activation and transmutation products and nuclear wastes).
Some examples of the utilization of "EPIT" materials in the three general categories of reactors, i.e., thermal, breeder, and controlled thermonuclear reactors, will be reviewed. Many of the examples will deal with an attempt to avoid problems which arise from the interaction of neutrons with the materials in the reactor. other examples will deal with attempts to provide new or better nuclear fuels. Finally, a review of the nuclear wastes will be made to identify isotopes which can be recovered for beneficial purposes.

\subsection{Thermal Reactors}

7.1.1. Current Utilization on a somewhat limited scale the "EPIT" materials concept has been implemented in the fabrication of nuclear fuels, neutron moderators, and radiation shielding components of thermal reactor systems. These materials must conform to highly restrictive nuclide and elemental purity specifications. Uranium enriched in uranium-235 with certain restrictions on element purity have been the main nuclear "EPIT" fuel material for the thermal reactor. Lithium-6, by virtue of its large thermal neutron absorption cross section and nonemission of gamma radiation, has been used extensively as shielding material against slow neutrons. It is especially desirable because it is converted to tritium and nonradioactive helium upon neutron capture. Lithium, which is highly enriched in lithium-7, has a small neutron absorption cross section, making it useful as a $\mathrm{pH}$ buffer in the form of lithium-7 hydroxide for the pressurized water reactor. Lithium-7 is also a candidate moderator material in high temperature reactors and a nuclear fuel constituent for the homogeneous reactors. Similarly, boron-10, because of its large thermal neutron absorption cross section, has been utilized for shielding material and control rods in the various thermal reactors.

To meet the requirements for lithium and boron, a private company ${ }^{2}, 24$ recently announced plans for the construction of two large isotope separation and purification plants. They have estimated a market for lithium-7 at approximately $1,000 \mathrm{~kg} / \mathrm{yr}$ and a unit selling price of $\$ 2,500-\$ 3,00 \gamma \mathrm{kg}$ of enrichment to 99.998 lithium-7. The plant to produce highpurity boron-10 crystalline powder is 
being built under an agreement with ERDA to provide neutron absorption material for use in various research and production programs.

7.1.2. Future Trends As designs for thermal reactors become more advanced and sophisticated, optimizing the performance of their structural components by use of "EPIT" materials should occur. Indeed some of these applications already have been proposed. An early "EPIT" materials application was proposed by Gross. 25 Hc suggested that titanium-50 be used in place of zirconium for fuel cladding in thermal reactor systems. The alloys of titanium metal show very good properties for high temperature applications, and titanium- 50 has a very small absorption cross section (140 mb) for thermal neutrons. It is suggested that use of titanium-50 could result in a neutron economy which would more than offset the additional cost for the isotopic enrichment. Unfortunately, the necessary data to confirm this suggestion are not available at the present time.

Another proposed "EPIT" material application concerns optimization of the zircalloy fuel cladding for the heavy water CANDU reactor. Neutron absorption by the zirconium isotope in the heavy water system is the dominant nonfue]. neutron loss mechanism. It has been estimated ${ }^{26}$ that about 708 of neutron absorption by zircalloy cladding is by the zirconium-91 isotope (60\%) and the hafnium-177 impurity (108). Optimization of the zircalloy cladding for the CANDU reactor could improve the neutron eculliny resulting ${ }^{26}$ in a reduction of the Euel loading of about $6 \%$ and an increase in the conversion ratio of about 5-6\%. At current fuel costs, the estimated dollar savings over the lifetime of the reactor could amount to as much as $\$ 3,000,000$.

The thermal reactors which will dominate at least until the middle 1980's are light-water enriched-uranium-fueled reactors (pressurized and boiling water). Projected worldwide use of this type of reactor places a heavy burden on the fuel supply. To alleviate the fuel burden, it has been proposed ${ }^{7}$ that the unburned uranium fuel and reactor-produced plutonium fuel be recycled. Recycled uranium and plutonium fuels will contain considerably more elemental and isotopic impurities that have been introduced through burnup of enriched uranium than does virgin fuel. Obviously, for optimum use of recycled materials, the "EPIT" concept should be utilized.

The cost penalty for not optimizing recycled fuel can be significant. For example, the reactor-produced nuclides uranium-236 and plutonium-242 which are neither fertile nor fissile and, therefore, are considered parasitic neutron absorbers would have to be compensated for by increasing fuel loadings. One estimate of this penalty ${ }^{28}$ in a neutron economy, based on a, $10 \%$ recycled uranium containing about 0.12 . wt 8 uranium-236, is that it will require $2.8 \%$ more feed material, 4.18 more separative work, and about 28 increase in fuel cycle cost. The cost penalty for plutonium-242 in recycle fuel can be illustrated in terms of fissile plutonium value. The replacement value of a gram of fissile plutonium is only $83 \%$ of the value of a gram of fissile plutonium in the previous recycle fuel.

Further advantages to removing these impurities can be gained in lower fuel reprocessing cost. Their presence in the fuel leads to increased amounts of uranium-232 and plutonium-238, the presence of which dramatically increases recycle fuel preparation costs. The increased shielding and remote process handing equipment required because of the rapid buildup of the radioactive daughter products add significant costs.

Severe uranium shortage has also stimulated investigations $26,29,30$ to find other suitable nuclear fuels. One such effort has been to utilize the CANDU reactor which is a heavy-water moderated reactor with uranium-233/thorium fuel. Typically, the atom ratio of uranium to thorium for the equilibrium fuel is 2.6 with uranium isotopic compositions of $61 \%$ uranium-233, $23 \%$ uranium-234, 6\% uranium-235, 98 uranium-236, and only traces of uranium-232 and uranium-238. Feasibility of such breeder reactor systems appears to depend upon neutron economy. The neutron economy can be improved by applying the "EPIT" concept ${ }^{26}$ to zircalloy as previously mentioned and by increasing the heavy water enrichment by $0.18 \quad(99.88+99.98)$. This will alter the conversion ratio by 0.68 resulting in a 0.68 reduction in 
fissile loading and improving the feasibility of this reactor concept.

7.2. Fast Breeder Reactor Systems Opportunity for application. of "EPIT" materials in breeder reactors appears quite promising in several areas. Since many reactor designs are either being formulated or being tested, it appears reasonable that some consideration be given to the optimization of the fuel cladding similar to considerations that were proposed for cladding materials for the thermal reactor. However, the present survey did not identify any isotope applications in. this area. There does appear to be a need ${ }^{2}$ for improvement in the performance of the stainlesssteel fuel cladding that is proposed for the breeder reactors. "EPIT" components of stainless steel may very well provide the necessary options for optimized material performance.

"EPIT" materials are being evaluated as fuel components for some breeders to improve economics and to monitor operating characteristics. Nitrogen-15 is being evaluated ${ }^{31}, 32,33$ for use in the liquidmetal fast-breeder reactor (LMFBR) fuel, and isotopes of the rare gases (krypton, xenon, etc.) are scheduled for use as tags for early detection of leaks in fuel rods.

Advanced LMFBR fuels, (U, Pu) C and $(U, P u) N$, are being considered ${ }^{31,32}$ as replacements for oxide fuel owing to their superior breeding and linear power capability. Further improvement in the performance of nitride fuel is anticipated if nitrogen-15 is used rather than natural abundance nitrogen. Natural nitrogen contains $99.635 \%$ nitrogen-14 which has a rather large neutron absorption cross section $\left(10^{-3}\right.$ to $10^{-1}$ barns at high energies), whereas that of nitrogen-15 is considered. negligible. In addition, the use of nitrogen-15 removes the problems ${ }^{33}$ associated with carbon-14 which is produced by an $(n, p)$ reaction with nitrogen-14.

Preliminary economic analysis for the use of nitrogen-l'5 fuel for the LMFBR has been made, ${ }^{34}$ and the allowable costs for nitrogen-15 are summarized below:
Items

Core and Blankets

(pin diameters 0.3 to 0.45 in.)

Core Only

(pin diameters 0.3 to 0.45 in.)

The amount of nitrogen-15 that will be needed for development studies in the period 1976 to 1993 would probably range from about a kilogram/year to tens of thousands of kilograms/year. ${ }^{34}$ Based on anticipated increases in LMFBR electrical production for the period 1993 through 2019, it is estimated that $7,196,000 \mathrm{~kg}$ of nitrogen-15 (average of approximately $300,000 \mathrm{~kg} / \mathrm{yr}$ ) will be required if the LMFBR's are fueled with the nitride.

The cost benefits associated with the scaleup of established nitrogen isotope separation methods, such as No distillation, the Nitrox chemical exchange process, and membrane processes, were investigated ${ }^{34}$ to estimate the production costs for meeting these nitrogen-15 requirements. Preliminary estimates indicate that nitrogen-15 can be produced for less than the allowable costs previously mentioned. The $\mathrm{NO}^{-\mathrm{HNO}_{3}}$ chemical exchange process turned out to be the most economical process. The cost of production of 998 nitrogen-15 by this method appears to be $\$ 150$ to $\$ 265$ per kilogram of nitrogen.

With new and greater reactor reliability and efficiency demands, methods for early detection of leaks in reactor fuel elements are being investigated. One method for timely detection of leaks involves the use of a technique called "gas tagging". "Gas tagging" involves the use of predetermined quantities of enriched krypton and xenon isotopes that are added to the helium fill gas of the fuel rods for a given fuel assembly. In the event of a failure, the helium fill gas containing the "tag gas" escapes into the reactor coolant where it can be $\exists I$ sampled and analyzed by a mass spectrometer. The detection of the tag gas then makes possible the identification of the leak ing fuel element, and replacement of the Lis if 9.0 $2: 00$ 
defective fuel assembly can then proceed with minimum reactor shutdown time.

Although the "gas tagging" method was first proposed for use in fast breeder reactors, $35,36,37$ it may also be used to economic benefit ${ }^{38}$ in pressurized water reactors (PWR's) and boiling water reactors (BWR's).

7.3. Potential "EPIT" Materials in Controlled Thermonuclear Reactor (CTR) Systems Reactor costs and operating efficiencies are often dependent upon the interaction of neutrons and reactor containment materials. In the case of the CTR, the neutron reactions are further complicated by the fact that the neutron energy spectrum will vary from $14 \mathrm{MeV}$ down to near thermal energy levels at various positions in the reactor. Since these. reactions are a function of the properties (neutron absorption cross sections) of the nuclides of the structural materials, and large amounts of structural components are required, "EPIT" materials in large amounts may find application in this area.

The CTR blanket i.s the component that is most likely to benefit from the use of "EPIT" materials. Functions of the blanket in addition to neutronically breeding tritium are to 1) provide a vacuum envelope for the plasma, 2) convert the kinetic energy of the $14 \mathrm{MeV}$ neutrons into heat, and 3) provide a mechanism for transferring the heat. These functions can be optimized by the use of "EPIT" materials.

The use of enriched lithium- 6 for breeding of tritium has been evaluated under various design conditions. Preliminary studies indicated that only marginal costbenefits could be accomplished with enriched lithium-6. The gain in energy multiplication as the lithium- 6 isotope ratio increased was found to be $0.06 \%$. for $15 \%$ lithium- 6 and $0.5 \%$ for $50 \%$ lithium- 6 . With such small gains the adoption of this application will be determined by cost of the isotope enrichment. However, other considerations such as the tritium breeding ratio and the neutron attenuation in the blanket may change the criteria for the evaluation of the lithium enrichment.
Another potential application worthy of investigation is the construction material for the first wall of the blanket. According to the Wisconsin Tokomak Reactor design, ${ }^{39}$ it is envisioned that the wall will consist of approximately 480 metric tons of 316 stainless steel. Since the wall will be subjected to tine most severe high temperature neutron irradiation environment that has ever been imposed on an alloy, it is anticipated that the wall will have to be replaced every two years. In addition to a costly replacement, the neutron irradiation will produce undesirable activation and radioactive transmutations products 40 which will have to be aisposed of in an acceptable manner.

The short lifetime of the first wall is mainly the result of the degradation in the mechanical properties of the steel which is caused by void formation and swelling. It is believed 21,41 that voids and swelling are the result of the neutron displacement reactions and the helium gas produced by the $(n, \alpha)$ reactions. Because of the helium gas volume expansion at higher temperatures, the first wall operating temperature has to be kept below $550^{\circ} \mathrm{C}$, too low for annealing the displacement voids. It may be possible to increase the temperature above the annealing point if a way to reduce helium gas production by the $(n, \alpha)$. reactions can be found. An increased operating temperature may then not only increase the lifetime of the first wall, but also effectively increase the operating efficiency of the reactor.

A reduction in helium production may be pnssihle by applying the "EPIT" material concept to stainless steel. Removal of... nuclides present in metal constituents of stainless steel which have high $(n, \alpha)$ absorption cross sections could effectivelỳ reduce helium production. Approximately $65 \%$ of all helium produced in stainless steel is the result of $(n, \alpha)$ reactions of the iron isotopes. Based on available iron neutron absorption cross section data, it appears that a large amount 130 to 50\%) of the helium produced from the iron results from the iron-54 neutron reaction, ${ }^{5 \cdot 4} \mathrm{Fe}(\mathrm{n}, \alpha){ }^{51} \mathrm{Cr}$. Removal of iron-54, which is approximately $6 z$ of naturally occurring iron, could significantly reduce the helium production. Similar aonsiderations for. 
"isotopically tailoring" for other large helium producers, i.e., chromium, nickel, silicon, and carbon, can be made. In addition, removal of iron-54 will significantly reduce the amount of radioactive materials such as chromium-51 and manganese-54 which will be produced in the 316 stainless steel structural material of the CTR. It appears that processing nonradioactive materials to avoid production of radioactive waste would cost less than processing the radioactive waste and would be environmentally. more acceptable.

The value of "isotopically tailoring" in terms of reactor reliability and operaing efficiency must ultimately be weighed against the cost of the isotope depletion. Although scarcity of available experimental data (such as neutron absorption cross section values, mechanical property degradation mechanisms, and isotope separation costs) makes it difficult, if not impossible, to estimate this value at this time, it is, nevertheless, quite clear that a tremendous potential for dollar savings does exist.

The search for materials $2,43,44$ for construction of the CTR blanket is quite extensive. Scientists are looking at metals, alloys, and ceramics in an effort to find a material than can retain adequate strength, ductility, and dimensional stability in the CTR plasma environment. Unfortunately, each material that has been proposed so far has had serious limitations, most of which result from the interaction of the material with neutrons. Therefore, it is suggested that the next step is the investigation of the removal of undesirable nuclides from these materials. Tables 1 and 2 list some of the nuclideneutron reactions which produce some of the undesirable effects. Table 1 lists some of the commion metals, and Table 2 lists some of ceramic components which are under consideration for use in the CTR blanket. These tables are provided in an attempt to show the many options which can be made available by the use of the "EPIT" concept.

\section{AVAILABILITY OF "EPIT" MATERIALS FOR NUCLEAR APPLICATIONS}

In recent years the amount of research and development conducted on isotope separation processes has greatly increased the potential for future "EPIT" materials. Perhaps the most exciting, new approach to isotopic separations embraces the numerous laser isotope separation (LIS) methods that are being developed. Although a large amount of this development comes from the attempt to provide lower cost uranium-235 nuclear fuel, much of the information obtained as a result of these studies will contribute to the development of isotope separation processes for other elements. Since the LIS method is one which involves high selectivity, it has great potential for reducing the energy requirements for separations. Further it can be utilized to obtain elemental purity 9,26 especially in cases where impurity levels are very low (ppm levels). As a result, the laser method can be an effective separation technique for the future to produce "EPIT" materials at a low energy expenditure and to provide materials not now available for optimization of the advanced nuclear energy systems.

For near-term production of "EPIT" materials, time proven isotope separation technigues are also available. Many of these methods ${ }^{12}$ have been or are capable of being significantly improved. With improvements, these methods may produce "EPIT" material on a favorable economical basis. Isotope production costs for many of these processes have been limited more by the scale of production, which for the most part has been determined by market demand, than by the state of the art.

Development of a variety of isotope separation processes is an important $R \& D$ activity, because there is no one isotope separation process which is economically superior to all others for every isotope. The best method of separation can be chosen only after an evaluation of the chemical and physical properties of nuclides involved, the degree of separation desired, the scale of the operation, 
Table 1

METALS FOR "EPIT" MATERIAL CONSIDERATIONS IN FIRST WALL AND BLANKET STRUCTURE COMPONENTS OF FUSION REACTORS

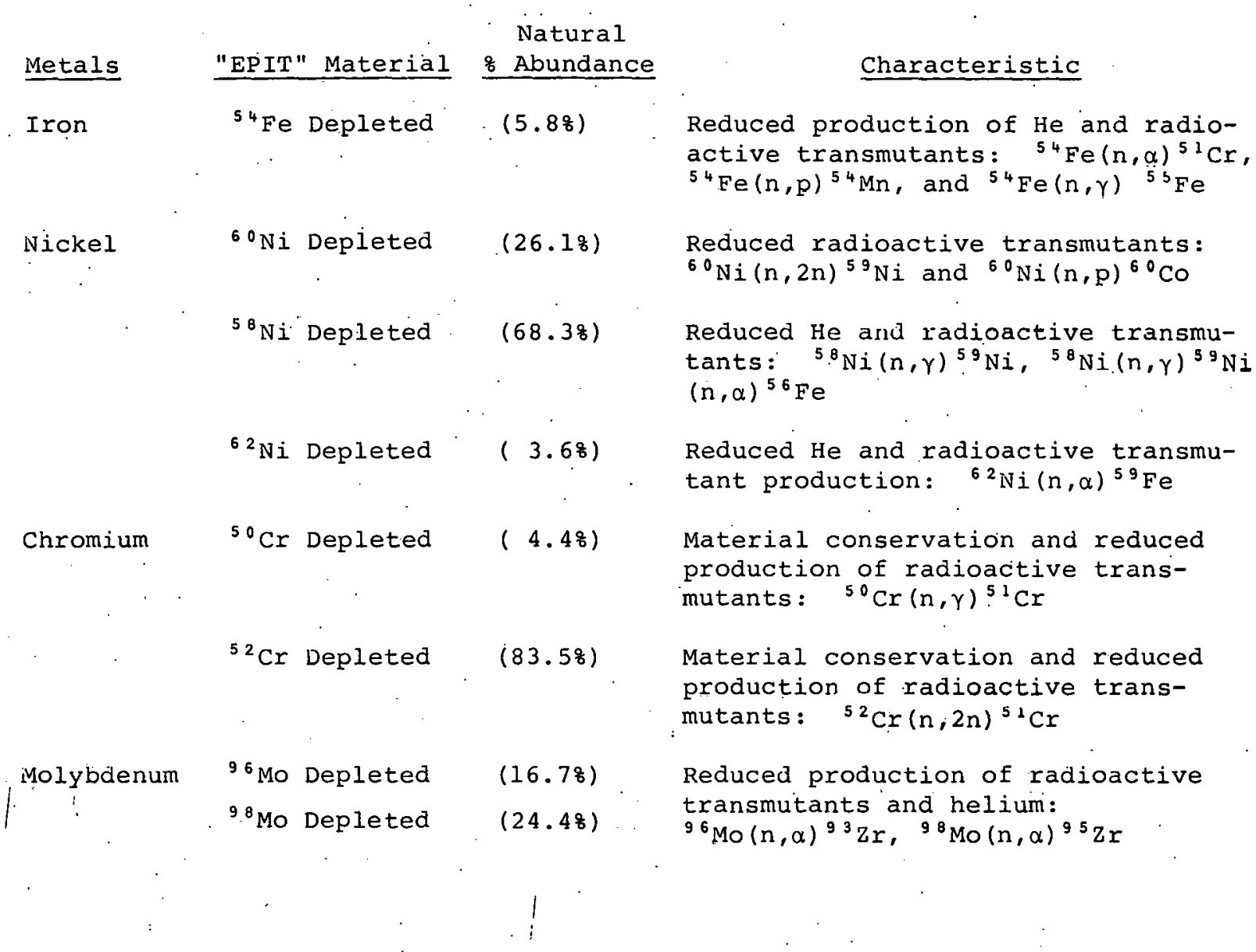


Table 2

CERAMIC MATERIALS FOR FUSION REACTOR SYSTEMS

\begin{tabular}{|c|c|c|c|c|}
\hline Ceramic & Interest & Proposed "EPIT" Material & $\begin{array}{ll} & \text { Natural } \\
8 \quad \text { Abundance } \\
\end{array}$ & Desired Property \\
\hline \multirow[t]{2}{*}{ SiC } & $\begin{array}{l}\text { First wail } \\
\text { and blanket } \\
\text { structural } \\
\text { components }\end{array}$ & $\begin{array}{c}{ }^{13} \mathrm{C} \text { Depleted } \\
\therefore\end{array}$ & $(1.11 \%)$ & 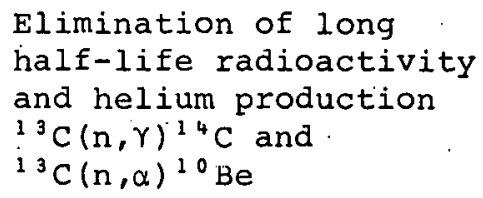 \\
\hline & & ${ }^{30} \mathrm{Si}$ Depleted & $(3.118)$ & $\begin{array}{l}\text { Reduction of decay } \\
\text { heat }{ }^{30} \mathrm{Si}(\mathrm{n}, \mathrm{\gamma})^{31} \mathrm{Si}\end{array}$ \\
\hline $\mathrm{Si}_{3} \mathrm{~N}_{4}$ & $\begin{array}{l}\text { First wall } \\
\text { and blanket } \\
\text { structural } \\
\text { components }\end{array}$ & ${ }^{14} \mathrm{~N}$ Depleted & $(99.648)$ & $\begin{array}{l}\text { Elimination of long } \\
\text { half-life radio- } \\
\text { activity }{ }^{14} \mathrm{~N}(\mathrm{n}, \mathrm{p}){ }^{1{ }^{4} \mathrm{C}}\end{array}$ \\
\hline . & & & & ${ }^{14} N(n, p){ }^{14} C$ \\
\hline $\mathrm{B}_{4} \mathrm{C}$ & $\begin{array}{l}\text { First wail } \\
\text { and blanket } \\
\text { structural } \\
\text { components }\end{array}$ & ${ }^{10} \mathrm{~B}$ Depleted & $(19.88)$ & $\begin{array}{l}\text { Reduction of Helium } \\
\text { due to }{ }^{10} B(n, \alpha)\end{array}$ \\
\hline
\end{tabular}


Table 2 (Continued)

\begin{tabular}{|c|c|c|c|c|c|c|}
\hline Ceramic & Interest & Proposed & "EPIT" & Material & $\begin{aligned} & \text { Natural } \\
& \text { \% } \text { Abundance } \\
&\end{aligned}$ & Desired Property \\
\hline Beo & $\begin{array}{l}\text { Neutron } \\
\text { multipli- } \\
\text { cation }\end{array}$ & ${ }^{16} \mathrm{O}$ Dep & eted & . & $(99.88)$ & $\begin{array}{l}\text { Removal of }{ }^{16} \mathrm{O}(\mathrm{n}, \mathrm{p}) \\
\text { and }{ }^{16} \mathrm{O}(\mathrm{n}, \alpha) \\
\text { reactions }\end{array}$ \\
\hline B & $\begin{array}{l}\text { Blanket } \\
\text { poison }\end{array}$ & ${ }^{10} . \mathrm{B} \operatorname{En} x$ & ched & & $(19.98)$ & $\begin{array}{l}\text { Lower tritium pro- } \\
\text { duction; large cross } \\
\text { section for reaction } \\
\mathrm{B}(\mathrm{n}, \alpha) \text { yields soft } \\
\text { gamma }(0.5 \mathrm{MeV}) \text {; } \\
\text { produces about as much } \\
\text { energy as displaced } \\
{ }^{6} \mathrm{Li}\end{array}$ \\
\hline
\end{tabular}


the capital investment, the energy consumption, and the operating and maintenance costs for each competing separation process.

The availability of a variety of isotope separation methods also allows the option of combining two or more separation processes for a more economical isotope production. A recent example ${ }^{45}$ is the combination of laser techniques to increase deuterium concentrations to where conventional enrichment processes will work more economically.

\section{9. "EPIT" MATERIALS FROM NUCLEAR WASTES FOR BENEFICIAL USES}

The development of isotope separations and elemental purity techniques that are required for the fabrication of "EPIT" recycled plutonium and uranium fueis can also provide an inexpensive means for the fractionation of high-level wastes. Fractionation refers to the recovery and purification of nuclear waste constituents for beneficial uses. Large-scale recovery of the more than 40 elements present in nuclear wastes will require changes in proposed processing and management procedures which are difficult to assess on a risk-cost-benefit basis at this time because of a lack of process data and an established market for most. of these materials. Therefore, much of the cost-benefit data which exist are highly subject to change.

It appears, however, with the advancement of economic separation processes and the increased requirements for special materials, that the time is rapidly approaching when these materials will be recovered on a large scale. For these reasons the constituents of nuclear wastes that have been identified as most likely to be used beneficially were briefly reviewed.

Some of the isotopes $46,47,48,49,50,51$ from the nuclear fuel by-product that have been identified as having potentially beneficial uses, are summarized below:

$$
\text { Krypton-85 Curium-242, }-244
$$

Strontium-90 Plutonium-238

Technetium-99 Rhodium-103

\author{
Neptunium-237 Ruthenium-106 \\ Americium-241 Cesium-137 \\ Carbon -14 \\ Promethium-147 \\ Hydrogen -3 \\ Stable Isotopes of \\ Xenon and Palladium
}

Studies concerning the risk-cost-benefits on the availability and uses for many of these isotopes are being made. Krypton85 has been proposed ${ }^{52}$ for use as selfluminous lights; heat sources for direct energy conversion; and radiation sources for nondestructive testing, for gaging and intrusion devices, and for waste treatment. Strontium-90, cesium-137, curium-144, promethium-147, americium-241, and plutonium-238 have been proposed for a number of uses. ${ }^{3}$ Palladium, rhodium, ruthenium, and technetium are proposed as substitutes for natural platinum metals. 54 The platinum metals occur in small concentrations $(0.2$ to $0.3 \mathrm{oz} /$ ton $)$ in natural ore, whereas in spent nuclear fuel they can be considerably more concentrated ( $\sim 90 \mathrm{oz} / \mathrm{ton})$.

Nuclear fuel wastes present a very favorable source of platinum metals, especially since the U. S. imports virtually all its platinum metals from foreign sources and its reserves can be very small at certain times compared to the annual consumption. To illustrate the significance of this source: in 1975 more fission product ruthenium was produced by reactors than is currently consumed, and by 1980 production of fission product rhodium will approximate current U. S. yearly consumption.

Although a potential market exists for rhodium, palladium, ruthenium, and technetium, early appraisals ${ }^{54}$ of the cost of recovery and the marketability of these radioactive metals did not show economic feasibility. These evaluations should be continued with the additional considerations of decontamination which use isotope separation techniques ("EPIT" materials concept). This may allow satisfactory return on investment especially on ruthenium and rhodium. 


\section{REFERENCES}

1. C. C. Thomas, Jr., and K. K. Spillay, "Application of Activable Tracers to Criminalistics," Trans. Am. Nucl. Soc.,23, 102 (1976).

2. G. G. Eichholz, "Use of Actjvable Tracers in Water Treatment Systems," Trans. Am. Nucl. Soc., 23, 102 (1976).

3. W. A. Jester, "Field Use of Neutron Activable Tracers," Trans. Am. Nucl. Soc., $23,102(1976)$.

4. W. A. Jester and K. A. Uhler, "Identification and Evaluation of Water Tracers Amenable to Post-Sampling Neutron Activation Analysis," PSU Institute for Land and water Resources, Research Pub. No. 85 (1974).

5: V. P. Guinn, "Activation Analysis with Particular Attention to the Detection of Stable Isotopes," in Isotopes in Experimental Pharmacology, pp. 23-32,

L. J. Roth (ed.), The University of Chicago Press, Chicago, IL., 1965.

6. C. A. Clomski, "Activable l'racers in Medicine," Trans. Am. Nuc1. Soc., 23, 102 (1976).

7. J. J. Katz, R. A. Uphaus, and H. L. Crespi; "Isotope Chemistry and Biology," in Isotopes and Chemical principles, pp. 184-205, Peter A. Rock (ed.), ACS Symposium Series 11, American Chemical Society, Washington, DC, 1975.

8. W. C. Davis, "Stable Isotope Customer List and Summary of Shipments - FY-1975," ORNL-TM-5089, Oak Ridge National Laboratory. (Oct. 1975).

9. E. Stark, Jr., "Solution Looking for a Problem," Ind. Res., 18, 78-82 (1976).

10. B. E. Jepson and R. DeWitt, "Separation of Calcium Isotopes with Macrocyclic Polyether Calcium Complexes," J. Inorg. Nucl. Chem., 38, 1175-1177 (1976).

i1. William Spindel, "Isotope Separation Processes," in Isotopes and Chemical Principles, P. A. Rock (ed.), Chapter 5, p..77, ACS Symposium Series 11.

12. R. A. Schwind and W. M. Rutherford, "Stable Isotope Enrichment by Thermal Diffusion, Chemical Exchange, and Distillation," Proceedings of Symposium on New Developments in Radiopharmaceuticals and Labeled Compounds, Copenhagen, Denmark, IAEA/SM-171-47, March 1973.

13. R. Dewitt, R. A. Schwind, and B. E. Jepson, "Process for Separating Sulfur Isotopes," U. S. Patent No. 3,869,255 (3/4/75).

14. Glenn T. Seaborg, "Peaceful Uses of Nuclear Energy - A Collection of Speeches," Division of Technical Information, U. S. AEC, July 1970.

15. J. P. Holdren, T. K. Fowler and R. F. Post, "Fusion Power and the Environment," UCRL-76911 (preprint), Lawrence Livermore Laboratory (June 2, 1975).

16. F. N. Fiakus, "Fusion Power and the Environment," At. Energy Rev., 13,588 $(1975)$.

17. "Proceedings of the Magnetic Fusion Energy Blanket and. Shield Workshop; A Technical Assessment": Held at Brookhaven National Laboratory, Upton, NY, 11973 March 29-Aprii 2, 1976, ERDA-76/.117/1. 
18. A. L. Hammond, "Lithium: Will Short Supply Constrain Energy Technologies?" Science, 191, 1037 (1976).

19. J. A. Richardson, "Shortage of Highly Enriched Lithium-7," Nucl. Eng. Intern., 21, 29 (1976).

20. E. V. Anderson, "Who Pays is Key to Helium's Future," Chem. Eng. News, 54, $11(1976)$.

21. "Report to the American Physical Society by the Study Group on Physics Problems Relating to Energy Technologies: Radiation Effects on Materials," Rev. Mod. Phys., 47, Suppl. No. 3, Winter 1975.

22. G. R. Hopkins, "Estimation of Impurity Radiation Loss From Fusion Reactor Plasmas," Proc. Symp. Technology of Controlled Thermonuclear Fusion Experiments and Engineering Aspects of Fusion Reactors, Austin, TX, Conf-721111, p. 795 (1972).

23. Nucleonic Week, p. 10 (February 26, 1976).

24. Chemical and Engineering News, p. 15 (September 20, 1976).

25. R. W. F. Gross, "Laser Isotope Separation," Opt. Eng:, 13:6, 506 (1974).

26. A. W. Johnson, "Laser Isotope and Element Purification of Zircaloy Clad," personal communication, Sandia, Albuquerque, NM.

27. Savannah River Laboratory Quarterly Report, "Light Water Reactor Fuel Recycle," DP ST-LWR-1976, Jan-Mar 1976, Aiken, SC.

28. "Alternatives for Managing Wastes From Reactors and Wastes From Reactors and Post-Fission Operations in the LWR Fuel Cycle", ERDA-76-43, May 1976.

29. E. Critoph, S. Barerjee, F. W. Barclay, D. Hamel, M. S.. Mitgram, and J. I. Veeder, "Prospects for Self-Sufficient Equilibrium Thorium Cycles in CANDU Reactor," Trans. Am. Nucl. Soc., 22, 706 (1975).

30. A. M. Perry and A. M. Weinberg, "Thermal Breeder Reactors," Ann. Rev. Nucl. Sci., 22, $317(1972)$.

31. Y. I. Chang and W. P. Barthold, "Impact of Nitrogen Enrichment on Breeding Performance of LMFBR Nitride Fuel," Trans. Am. Nucl. Soc., 21, 407 (June $1975)$.

32. Arthur A. Bauer, "Nitride Fuels: Properties and Potentials," React. Technol., 15, $287(1972)$.

33. V. J. Tennery, E. S. Bower, W. D. Bond, S. V. Kaye; L. E. Morse and J. E. Till, "Potential Generation and Radiological Impacts of Gaseous $14 \mathrm{C}$ Released During Reprocessing of Advanced LMFBR Fuels," ORNL/TM-5538, June 1976 .

34. V. J. Tennery, "Nitrogen-15 Enrichment and its.Potential Use in Advanced LMFBR Mixed-Nitride Fuels," ORNL/TM-5621.

35. P. B. Henault, W. J. Larson, R. E. Rice, and C. W. Wilkes, "Progress in Xenon Tagging," Trans. Am. Nucl. Soc., 13, 797 (1970). 
36. N. J. McCormick and R. E. Schenter, "Gas Tag Identification of Failed Fuel, I. Synergistic Use of Inert Gases," Nucl: Technol:, 24, 149 (1974).

37. R. B. Kidman, "FTR Tag Burnup," Trans. Am. Nucl. Soc., 21,452 (1975).

38. K. C. Gross and W. J. Roos, "Dynamic Behavior of Tag Gas Isotopes in PWR Primary Coolant After Fuel Failure," Trans. Am. Nucl. Soc., 24, 396 (1976).

39. "Wisconsin Tokamak Reactor Design,". UWFDM-68, Vol. 1, Nuclear Engineering Department, University of Wisconsin (March 15, 1974).

40. W. F. Vogelsang, G. L. Kulcinski, R. G. Lotland, and T. Y. Sung, "Transmutation, Radioactivity, and After Heat in a Deuterium-Tritium Tokamak Fusion. Reactor," Nucl. Technol., 22, 379 (1974).

41. G. L. Kulcinski, D. G. Doran, and M. A. Abdou, in "Comparison of Displacement and Gas Production Rates in Current Fission and Future Fusion Reactors," Properties of Reactor Structural Alloys After Neutron or Particle Irradiation, $\triangle$ STM STP 570, American Society for Testing and Materials, 1975 , pp. 329-351.

42. M. L. Williams, R. T. Santoro, and T. A. Gabriel, "The Calculated Performance. of Various Structural Materials in Fusion Reactor Blankets," Nucl. Technol., 29, $384(1976)$.

43. M. A. Abdou, L. J. Wittenberg, and. C. W. Maynard, "A Fusion Design Study of Nonmobile Blankets with Low Lithium and Tritium Inventories," Nucl. Technol., 26, 400 (1975).

44. L. H. Rovner and G. R. Hopkins, "Ceramic Materials for Fusion," Nucl. Technol., 29, 274 (1976).

45. G. Karen, U. P. Oppenheim, D. Tol, M. Okon, and R. Weil, "Deuterium Separation in Formaldehyde by an Intense Pulsed $\mathrm{CO}_{2}$ Laser," Appl. Phys. Lett., $29: 1,40$ (1976).

46. C. M. Heeb, "The Availability of Useful Isotopes From Civilian Nuclear Power Reactors to the Year 2000," BNWL-B-435, Battelle Pacific Northwest Laboratories, Richland, WA (July 1975).

47. D. E. Deonigi, R. W. McKee, and D. R. Haffner, "Isotope Production and Availability From Power Reactors," BNWL-716, Battelle-Northwest Laboratory, Richland, WA (July 1968).

48. M. Timm, "Some Aspects of Nuclear Fuel Economics," IAEA Bull. 13, 695 (1975).

49. G. P. Dix, "The Beneficial Utilization of Nuclear Waste Products," Waste Management, 7.5, 153-175 (1975).

50. C. A. Rohrman, "Values in Spent Fuel From Power. Reactors," Isotopes and Radiation Technology, 6, 19 (1968).

51. Progress Report: Beneficial Uses Program, Period Ending December 31,1975, Sandia 75-0065, Sandia Laboratories (February 1976).

52. W. E. Gawthrop and P. E. Eg.gers, "An Assessment of the Potentially Beneficial Uses of $85 \mathrm{Kr}$," Trans. Am. Nucl. Soc., 23, 126 (1976). 
53. W. E. Sande and R. A. Libby, "Potential Sources for the Radiation Treatment of Food," BNWL-SA-5850, Battelle Pacific Northwest Laboratories, Richland, WA (June 6,1976 ).

54. L. I. Clark, F. D. Roberts, J. C. Sheppard, and J.. D. Kaser, "A Market Analysis of the Fission Products Rh, Pd, Ru, and Tc," BNWL-1690, BattelleNorthwest, Richland, WA (February 1973). 
DISTRIBUTION

\section{EXTERNAL}

TID-4500, UC-23 (2)

J. A. Chacon, DAO (15)

R. K. Flitcraft, MRC

N. Haberman, ERDA/DNRA (15)

W. J. Haubach, ERDA/DPR (2)

D. W. King, ALO (2)

\section{INTERNAL}

V. L. Avona (2)

W. T. Cave

R. DeWitt

C. W. Huntington

D. I. Jeojon

L. V. Jones

J. R. McClain

E. D. Michaels

W. J. RoOS

W. M. Rutherford

R. A. Schwind (5)

W. L. Taylor

R. M. Watrous

I. J. Wi.ttenberg

R. E. Valiée

Library (15)

Publications (15) 